\title{
Comparison of the Snellen and Spectrum LogMAR visual acuity charts in schoolgoing children
}

\begin{tabular}{|c|c|}
\hline \multicolumn{2}{|c|}{ 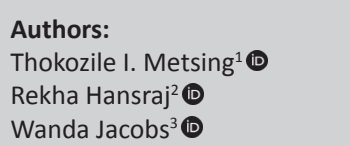 } \\
\hline \multicolumn{2}{|c|}{$\begin{array}{l}\text { Affiliations: } \\
{ }^{1} \text { Department of Optometry, } \\
\text { University of Johannesburg, } \\
\text { Johannesburg, South Africa }\end{array}$} \\
\hline \multicolumn{2}{|c|}{$\begin{array}{l}{ }^{2} \text { Department of Optometry, } \\
\text { University of KwaZulu-Natal, } \\
\text { Durban, South Africa }\end{array}$} \\
\hline \multicolumn{2}{|c|}{$\begin{array}{l}\text { Department of Nursing, } \\
\text { University of Johannesburg, } \\
\text { Johannesburg, South Africa }\end{array}$} \\
\hline \multicolumn{2}{|c|}{$\begin{array}{l}\text { Corresponding author: } \\
\text { Thokozile Metsing, } \\
\text { ingridm@uj.ac.za }\end{array}$} \\
\hline \multicolumn{2}{|c|}{$\begin{array}{l}\text { Dates: } \\
\text { Received: } 03 \text { Sept. } 2019 \\
\text { Accepted: } 09 \text { Apr. } 2020 \\
\text { Published: } 30 \text { July } 2020\end{array}$} \\
\hline \multicolumn{2}{|c|}{$\begin{array}{l}\text { How to cite this article: } \\
\text { Metsing TI, Hansraj R, } \\
\text { Jacobs W. Comparison of } \\
\text { the Snellen and Spectrum } \\
\text { LogMAR visual acuity charts } \\
\text { in schoolgoing children. } \\
\text { Afr Vision Eye Health. } \\
\text { 2020;79(1), a531. https://doi. } \\
\text { org/10.4102/aveh.v79i1.531 }\end{array}$} \\
\hline \multicolumn{2}{|c|}{$\begin{array}{l}\text { Copyright: } \\
\text { (c) 2020. The Author(s } \\
\text { Licensee: AOSIS. This } \\
\text { is licensed under the } \\
\text { Creative Commons } \\
\text { Attribution License. }\end{array}$} \\
\hline \multicolumn{2}{|l|}{ Read online: } \\
\hline 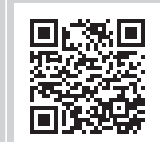 & $\begin{array}{l}\text { Scan this QR } \\
\text { code with your } \\
\text { smart phone or } \\
\text { mobile device } \\
\text { to read online. }\end{array}$ \\
\hline
\end{tabular}

Background: This article is part of a doctoral study conducted by Dr T.I. Metsing under the supervision of Dr W. Jacobs and Dr R. Hansraj.

Aim: To investigate the equivalence of a standard Snellen chart to that of the Spectrum LogMAR chart amongst children of school-going age.

Setting: The study was conducted through the University of Johannesburg, with data collected from the district of Ekurhuleni in the province of Gauteng, in South Africa.

Methods: Visual acuity (VA) data on uncompensated distance was collected from three randomly selected schools in Gauteng from 206 children aged between 6 and 17 years (mean age and standard deviation of $10.13 \pm 2.45$ years). Unaided monocular and binocular VAs were measured using the Snellen chart (SC) at $6 \mathrm{~m}$ and the Spectrum LogMAR chart (SLC) at $3 \mathrm{~m}$. Data was analysed using the Statistical Package for Social Sciences software.

Results: The mean VAs of both eyes (BE), right eye (RE) and left eyes (LEs) obtained using the SLC of 0.84 minutes (6/5), $0.91(6 / 5.5)$ and $0.96(6 / 5.8)$, respectively, fell within the normal ranges of $6 / 6$ or better. The mean VA scores of BE, RE and LEs obtained using the SC were $1.07 \mathrm{~min}(6 / 6.4)$, $1.11 \mathrm{~min}(6 / 6.7)$ and 1.18 (6/7.1), respectively, and fell below 6/6. The difference in the mean VAs scores for the SC and SLC of BE, RE and LE were found to be statistically significant $(p=0.00)$.

Conclusion: Monocular and binocular mean VAs for the SLC were found to be one line better than that for the SC. The slightly better performance of the SLC could be attributed to potential theoretical advantages of the LogMAR chart.

Keywords: Snellen chart; Spectrum Eyecare Software; LogMAR chart; visual acuity; children of schoolgoing age; optotypes; vision screening.

\section{Introduction}

Worldwide, most vision screening protocols rely on the measurement of Snellen visual acuities (VAs) to detect visual anomalies amongst children of schoolgoing age. This is despite some fundamental design flaws in the Snellen chart (SC), including non-geometric progression of letter or optotype sizes, the variable number of letters per line and the lack of a standardised scoring system. ${ }^{1}$ Difficulty in reading the SC is compounded by the contour interaction or visual crowding phenomenon, making legibility of some optotypes less satisfactory when presented with other optotypes in close proximity. ${ }^{2,3}$

There are recent studies comparing VAs that are evaluated using mobile software programmes, especially smartphones which compare favourably with conventional SC methods. ${ }^{4,5,6,7,8,9,10}$ The Spectrum LogMAR chart (SLC) in the eye care software program maintains consistent inter-optotype spacing, regardless of the angular subtense of the optotype, unlike the SC where such spacing is not necessarily equal. ${ }^{11}$

Perera et al. ${ }^{7}$ compared the SC VAs at $6 \mathrm{~m}$ and the reduced Snellen VAs iPad chart at $1.2 \mathrm{~m}$, on 88 adults recruited from the inpatient wards at a university teaching hospital in Melbourne, Australia. The largest mean differences ( $\geq 2$ lines) were found in patients with VAs equal to or worse than $6 / 18(n=5)$, suggesting that better VAs using the iPad chart were obtained, with not much difference detected for VAs better than 6/18. An obvious limitation of this study was the small number of participants who fell into the acuity range of $6 / 18$ or worse. Another limitation was differences in test distance for the iPad chart where patients with certain refractive errors would 
need to increase accommodation in order to focus on the chart. Small head movements at a closer distance are expected to cause a larger impact on the angle subtended by the optotypes. This observation may be more pronounced in patients with poorer VAs (worse than 6/18), and may partially account for the larger discrepancies between the two charts. ${ }^{7}$

In general, there appears to be a growing demand for the use of modern technology in the medical profession. The increasing interest is because modern technology is easy to use, fast, efficient and reasonably affordable depending on the type of device used. The other advantage of these devices is that they can be used in outreach community health screenings and school health programmes, by either trained health workers, teachers or other workers. Various applications are available for use on iPads, iPhones, iPods or other devices. ${ }^{4,5,6,7,8,9,10,11}$

Time constraints, space allocation and an increased workload are common challenges when the SC is used for mass school vision screenings. Lodha ${ }^{9}$ stated that these challenges relate to the time-consuming nature of using the SC and space allocation (usually $6 \mathrm{~m}$ ), which may be overcome by using simple and relatively inexpensive smartphones at a distance of $2 \mathrm{~m}$ for measuring VAs. However, notwithstanding the advantages of using modern technology, the validity of this method of vision screening should be further investigated before it is recommended for widespread vision screening program.

Currently there appear to be almost no studies or literature supporting the clinical use of the SLC compared to the SC. Therefore, this study sought to contribute to this deficiency in knowledge and compare VAs measured with SLC software, to establish clinical equivalency of this method to that of standard 6 m Snellen VA charts.

\section{Method}

This study and its methodology were approved by the University of Johannesburg Research Ethics Committees and the Province Protocol Review Committee. The tenets in the Declaration of Helsinki ${ }^{12}$ were followed in this study. Its research design was cross-sectional, comparative, descriptive and prospective, with a quantitative approach. ${ }^{13}$ Data were collected on only one occasion from 206 study participants, randomly selected from three phases in quintile 1 to 2 schools (schools for children from disadvantaged socio-economic backgrounds) from foundation (6-9 years old), intermediate (10-12 years old) and senior (13-16 years old) phases of learning in Johannesburg, in the province of Gauteng South Africa. Included in the study population were children, aged between 6 and 16 years, from mainstream quintile 1 and 2 schools, in Johannesburg, an urban area in South Africa. Excluded were children from quintile 3 to 5 schools, those from schools for the learning disabled, private schools and those wearing spectacles. The vision screenings were conducted over a period of three months on Wednesdays and Thursdays from $08 \mathrm{~h} 00$ until 12h00. Data were collected from two stations manned by the researchers, and the VAs of each participant were obtained using two different methods (SC and Spectrum software program). For each participant, VAs were measured three times, with the averages calculated. This was measured monocularly and binocularly using both the SC and SLC. Statistical analysis via SPSS software was used for descriptive statistics. Paired correlation tests and Bland-Altman plots were used to compare monocular and binocular VAs for the two methods, with the statistical significance set at $p<0.05$. The presentation of the $95 \%$ limits of agreement, using the Bland-Altman plots, were used in this study for the purpose of visual judgement of how well the two methods of measurement agree. ${ }^{14}$

\section{Snellen visual acuity chart}

Distance VAs were evaluated using the SC at $6 \mathrm{~m}$. The rooms in which the VAs were measured were well-lit, with subdued ambient room lighting and maximum natural lighting (sunlight). However, all glare was reduced with the lighting not directly on the surface of the chart to avoid glare or reflections. The SC was mounted on the wall at the child's eye level. The height of the chart was continuously adjusted to the eye level of the study participant concerned and only the uncompensated VAs were measured.

The measurement of the VAs started with the 20/50 (6/15) line, and on successfully identifying optotypes in that line, the examiner moved progressively down to the $20 / 20(6 / 6)$ line. Study participants who were unable to read the $20 / 50(6 / 15)$ line were asked to identify the letters above the failed line (e.g. the 20/60 [6/20]). The last line read correctly with each eye and then with both eyes was recorded. No misses were allowed for lines with less than three optotypes, only one miss was allowed for lines with 4-7 optotypes, and two misses were allowed for lines with 8-11 optotypes, as recommended by Proctor in the Department of Education (Colorado). ${ }^{15}$

Even though 20/20 (6/6) VA is regarded as representing standard normal vision, 20/30 (6/9) vision in the paediatric population is regarded as acceptable. ${ }^{16}$ In this study, rather than using the criteria for a fail or pass, the measurements of the VAs were put into three categories: normal (6/3.8 [0.63] $6 / 6$ [1.00]), slightly reduced (6/6.1 [1.05] - 6/9.5 [1.82]) and significantly reduced $(6 / 12[2.10]-6 / 60[10.00]) .{ }^{17}$

Younger participants in the foundation phase of learning were evaluated using the Snellen illiterate/tumbling E. A plastic demonstrator ' $\mathrm{E}$ ' was used by the examiner to evaluate participants lacking dexterity or cognition, to match the directional orientation in space. ${ }^{16}$ The examiner explained and demonstrated to the participants how to respond to the test. Targets were presented to the study participants in the same sequence as the SC, with the starting point being the $20 / 200$ line, to ensure that the study participants understood the test. Thereafter, the measurements of the VAs started with the $20 / 50(6 / 15)$ line, and on successfully identifying the direction of the letter E on that line, the examiner progressively moved down to the 20/20 (6/6) line. 


\section{Procedure on Spectrum Eyecare Software}

The Spectrum Eyecare Software is packed with approximately 200 tests including VA charts, balance, a test for astigmatism, and binocular and auxiliary tests, such as for the evaluation of muscle paresis (Hess screen). The program has various advantages including a comprehensive library and letters that can be calibrated to any size. The software has LogMAR Snellen letters, Early Treatment Diabetic Retinopathy Study (ETDRS), tumbling Es/Landolt Cs and LEA symbols. The range of VAs using the LogMAR chart is wide, from $6 / 190$ to $6 / 3.8$ (and comparable to the Snellen range of $6 / 60-6 / 4.5$ ). In this study, version 6.0 of the Spectrum Eyecare Software was used. Visual acuities using this program were evaluated using the SLC with the letters calibrated for a $3 \mathrm{~m}$ testing distance. Monocular and binocular VAs at distance were evaluated, with each line consisting of five optotypes equally spaced over a white background with a monitor luminance of $342 \mathrm{cdm}^{-2}$. The same alphabetical optotype, procedures and criteria as those of the SC were utilised in measuring the VAs using the software program.

\section{Ethical consideration}

University of Johannesburg Research Ethics Committee, Ethical Clearance Number: AEC01-09-2014, 07/02/2014.

\section{Results}

A total number of two hundred and six (206) study participants randomly selected from three schools were successfully evaluated in this study using the SC and the SLC. The majority of participants were from the intermediate phase $(n=102,50 \%)$, followed by the foundation phase ( $n=64,31 \%)$, with the lowest number of participants from the senior phase $(n=40,19 \%)$.

The mean age of the whole sample was $10.13 \pm 2.45$ years. The ages of the participants were not evenly distributed, with slight negative skewness $(-0.96)$ due to the ages being clustered (63.6\%) around the age groups of 10 and 13 years. Recordings of measured VAs were converted to a minimum angle of resolution (MAR) instead of Snellen notation. An MAR of $\leq 1 \mathrm{~min}(6 / 6)$ was regarded as normal, $\geq 1.05(6 / 6.3)-$ $1.95(6 / 11.8)$ was regarded as slightly reduced and $\geq 2(6 / 12)-$ $10(6 / 60)$ was regarded as significantly reduced..$^{18}$ Nonparametric data analysis methods were used due to the skewed data obtained.

\section{Distance visual acuities of both eyes with the Snellen chart and Spectrum LogMAR chart}

The binocular distance VAs obtained using the SC and SLC in the range of $6 / 3.8(0.63)-6 / 6(1.00)$ were found to be high, at $82.8 \%$ and $85.6 \%$, respectively, compared to the slightly reduced and significantly reduced VAs. Although there were slight differences obtained using the two methods between the means of the three phases of learning (foundation, intermediate and senior), the VAs using the SLC fell within the normal range (of better than 6/6), and that of the SC fell within the normal to slightly reduced range. Slight differences were observed in comparing mean standard deviations (SD) of the SLC to that of the SC. The SD of the SLC (0.58) was found to be slightly reduced compared to that of the SC (0.90). This therefore suggests less variability of the scores for the VAs of BE, compared to those obtained using the SC.

\section{Distance visual acuities of the right eyes with the Snellen chart and Spectrum LogMAR chart}

The distance VAs of the REs obtained using the SC and SLC in the range of $6 / 3.8$ (0.63 $\mathrm{min})-6 / 6$ (1.00 $\mathrm{min})$ were found to be high at $82.8 \%$ and $80.7 \%$, respectively, compared to the slightly reduced and significantly reduced VAs (Figure 1). Although there were slight differences obtained using the two methods between the means of the three phases of learning (foundation, intermediate and senior), the VAs of the REs using both methods (SLC and $\mathrm{SC})$ fell within the slightly reduced range. Slight differences were observed in comparing mean standard deviations of the SLC to that of the SC. The standard deviation of the SLC (0.83 $\mathrm{min})$ was found to be slightly reduced compared to that of the SC (1.46 $\mathrm{min})$, therefore suggesting less variability in the VAs score for RE VAs compared to those obtained using the SC (Table 1).

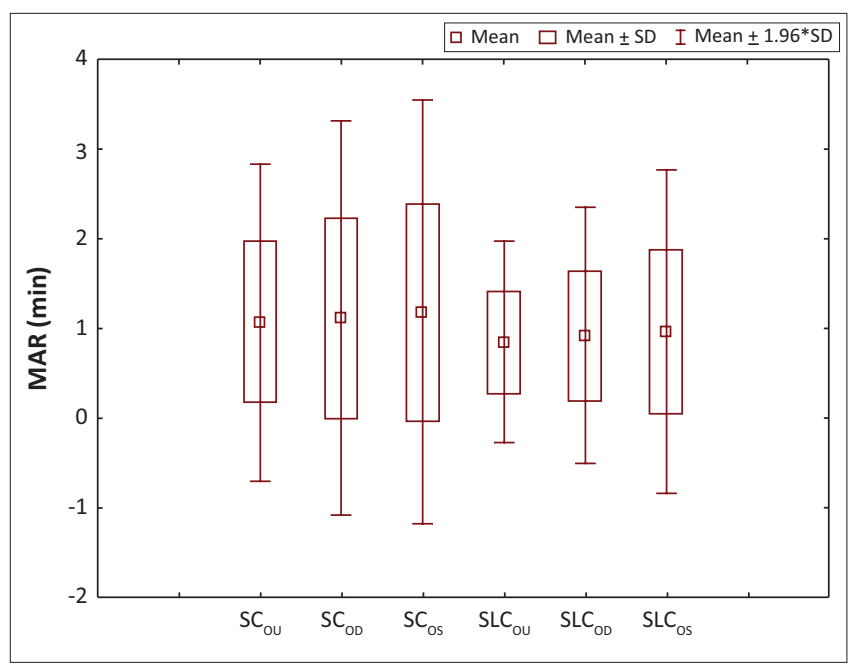

$\mathrm{SC}_{\mathrm{OU}^{\prime}}$ Snellen chart (both eyes); $\mathrm{SC}_{\mathrm{OD}}$, Snellen chart (right eye); $\mathrm{SLC}_{\mathrm{OU}}$, Spectrum LogMAR chart (both eyes); $S L C_{\mathrm{oD}^{\prime}}$, Spectrum LogMAR chart (both eyes); MAR, minimum angle of resolution; SD, standard deviation.

FIGURE 1: Box and whisker plots for the visual acuities scores obtained using the Snellen chart and Spectrum LogMAR chart for both eyes (OU), right eyes (OD) and left eyes (OS).

TABLE 1: Descriptive statistics for Snellen chart and Spectrum LogMAR chart mean differences for both eyes, right eyes and left eyes and distance visual acuities in minimum angle of resolution.

\begin{tabular}{llllll}
\hline \multicolumn{2}{l}{ SC \& SLC pairs } & Mean & $N$ & Std. deviation & Std. error mean \\
\hline \multicolumn{2}{l}{ Paired samples statistics } & & & & \\
Pair 1 & SC (BE) & 1.07 & 206 & 0.90 & 0.06 \\
& SLC (BE) & 0.84 & 206 & 0.58 & 0.04 \\
Pair 2 & SC (RE) & 1.11 & 206 & 1.11 & 0.08 \\
& SLC (RE) & 0.91 & 206 & 0.73 & 0.05 \\
Pair 3 & SC (LE) & 1.18 & 206 & 1.20 & 0.08 \\
& SLC (LE) & 0.96 & 206 & 0.92 & 0.06 \\
\hline
\end{tabular}

Note: Units are minutes throughout.

Std., standard; SC, Snellen chart; SLC, Spectrum LogMAR chart; BE, both eyes; RE, right eyes; LE, left eyes. 


\section{Distance visual acuities of the left eyes with the Snellen chart and Spectrum LogMAR chart}

The distance VAs of LEs obtained using the SC and SLC in the range of $6 / 3.8(0.63 \mathrm{~min})-6 / 6(1.00 \mathrm{~min})$ were found to be high at $73.2 \%$ and $83.2 \%$, respectively, compared to the slightly reduced and significantly reduced VAs (Table 3). Although there were slight differences obtained using the two methods between the means of the three phases of learning (foundation, intermediate and senior), the VAs using the SLC fell within the normal range (of better than 6/6), and that of the SC fell within the slightly reduced range (Figure 1). Slight differences were observed in comparing mean standard deviations of the SLC to that of the SC. The standard deviation of the SLC (1.21 $\mathrm{min})$ was found to be slightly reduced compared to that of the SC $(1.46 \mathrm{~min})$. This therefore suggests less variability of the VAs scores for LEs using the SLC, compared to those obtained with the SC (Table 1).

\section{Comparison of the visual acuities of the paired Snellen chart and Spectrum LogMAR chart obtained for both eyes, right eyes and left eyes}

Box plots for the VAs of BE, RE and LE obtained using the SLC are shorter compared to that of the SC. The shorter box plot of the VAs of BE, RE and LE obtained using the SLC suggests a high level of agreement compared to that of the SC, further demonstrated by the lower standard deviations. The variability of the VAs of BE, RE and LE scores obtained using the SC is indicated by the larger standard deviations (SD) (Figure 1). The mean value for the VAs of BE, RE and LE using the SC is slightly below 6/6 (1.00 $\mathrm{min})$ compared to that of the SLC (Table 1). This confirms that the VA scores of BE, REs and LEs obtained using the SLC fell within the normal range (of better than 6/6) compared to that of the SC.

The mean scores for the SC are consistently and significantly higher than for the SLC (BE, RE or LE). For example, the difference in the mean scores for SC BE (1.07) and SLC BE (0.84) is $0.22 \mathrm{~min}$; the test indicates that there is a statistically significant difference $(p=0.00)$ and this is true for the RE and LE (Table 2). In comparing the SC and SLC for the VAs scores for BE, the RE and LE, the mean difference between both methods is less than $0.50 \mathrm{~min}$, indicating clinically insignificant differences between

TABLE 2: Paired sample correlations of the visual acuities obtained using a Snellen chart and Spectrum LogMAR chart for both eyes, right eyes and left eyes.

\begin{tabular}{lccc}
\hline VA for BE, RE \& LE with SC \& SLC & $\boldsymbol{N}$ & Correlation & Sig. \\
\hline SC (BE) \& SLC (BE) & 206 & 0.77 & 0.00 \\
SC (RE) \& SLC (RE) & 206 & 0.69 & 0.00 \\
SC (LE) \& SLC (LE) & 206 & 0.81 & 0.00 \\
\hline
\end{tabular}

VA, visual acuiy; SC, Snellen chart; SLC, Spectrum LogMAR chart; BE, both eyes; RE, right eyes; LE, left eyes; Sig. significance. the means (Table 3). The Bland-Altman ${ }^{14}$ plots for each of the pairs for the SC and SLC of BE, RE and LE demonstrate the agreement between the two tests. The ranges of the mean differences (in $\mathrm{min}$ ) the limits of agreement (in $\mathrm{min}$ ), between which $95 \%$ of results lie, are $\pm 0.58, \pm 0.0 .81$ and \pm 0.70 standard deviation for $\mathrm{BE}, \mathrm{RE}$ and $\mathrm{LE}$, respectively, and are indicated in the plots. Results of BE VAs pair obtained with the SC and SLC (0.14-0.31) showed a narrow lack of $95 \%$ limits of agreement with each other, followed by the RE (0.09-0.31) and LE $(0.12-0.31)$ (Figures 2-4). This shows the better agreement of the VAs BE scores using the SC and SLC, compared to the VAs measured with the RE and LE.

\section{Discussion}

Visual acuity tests are the focus of most vision screening program to primarily determine amblyopia, refractive errors,

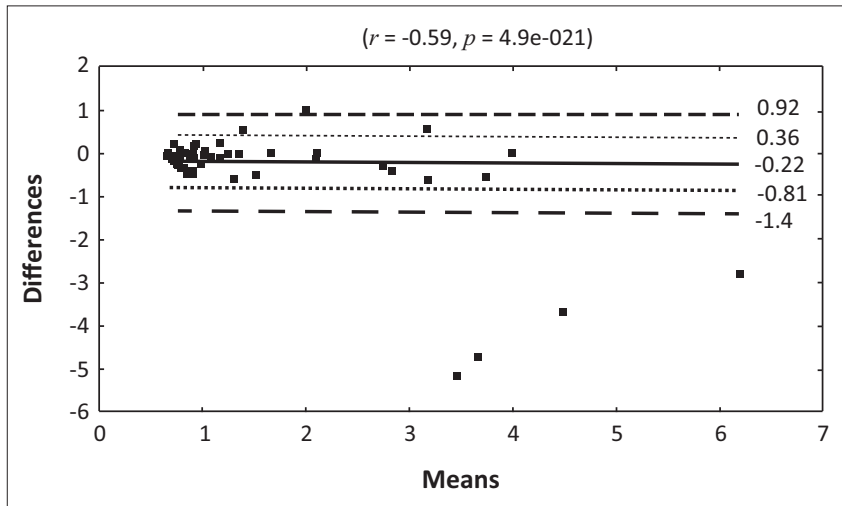

FIGURE 2: A Bland-Altman graph showing the agreement between scores of visual acuities (in min) for both eyes obtained with a Snellen chart and Spectrum LogMAR chart.

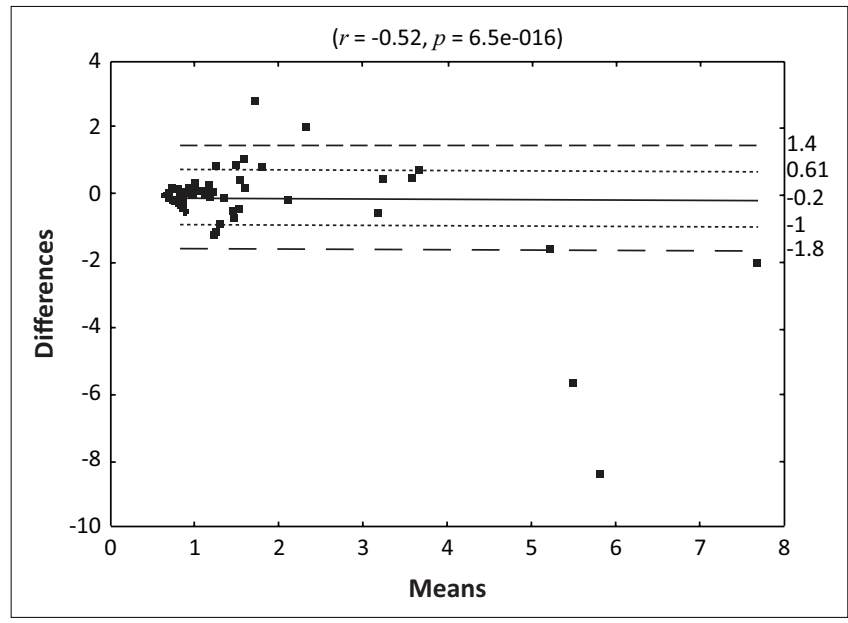

FIGURE 3: A Bland-Altman graph showing the agreement between scores of visual acuities (in min) right eyes obtained with a Snellen chart and Spectrum LogMAR chart.

TABLE 3: Mean differences (in min) of the visual acuities obtained with a Snellen chart and Spectrum LogMAR chart for both eyes, right eyes and left eyes.

\begin{tabular}{|c|c|c|c|c|c|c|c|c|c|}
\hline \multicolumn{2}{|c|}{ Paired samples test } & \multicolumn{5}{|c|}{ Paired differences } & \multirow[t]{3}{*}{$t$} & \multirow[t]{3}{*}{$D f$} & \multirow[t]{3}{*}{ Sig. (2-tailed) } \\
\hline & & \multirow[t]{2}{*}{ Mean } & \multirow[t]{2}{*}{ SD } & \multirow[t]{2}{*}{ SE } & \multicolumn{2}{|c|}{$95 \% \mathrm{Cl}$ of the difference } & & & \\
\hline & & & & & Lower & Upper & & & \\
\hline Pair 1 & $S C(B E)-S L C(B E)$ & 0.22 & 0.58 & 0.04 & 0.14 & 0.30 & 5.47 & 205 & 0.00 \\
\hline Pair 2 & $S C(R E)-S L C(R E)$ & 0.20 & 0.81 & 0.06 & 0.09 & 0.31 & 3.54 & 205 & 0.00 \\
\hline Pair 3 & $S C(L E)-S L C(L E)$ & 0.22 & 0.70 & 0.05 & 0.12 & 0.31 & 4.42 & 205 & 0.00 \\
\hline
\end{tabular}

SC, Snellen chart; SLC, Spectrum LogMAR chart; BE, both eyes; RE, right eyes; LE, left eyes; Sig. significance; SD, standard deviation; SE, standard error; CI, confidence interval; df, degree of freedom. 


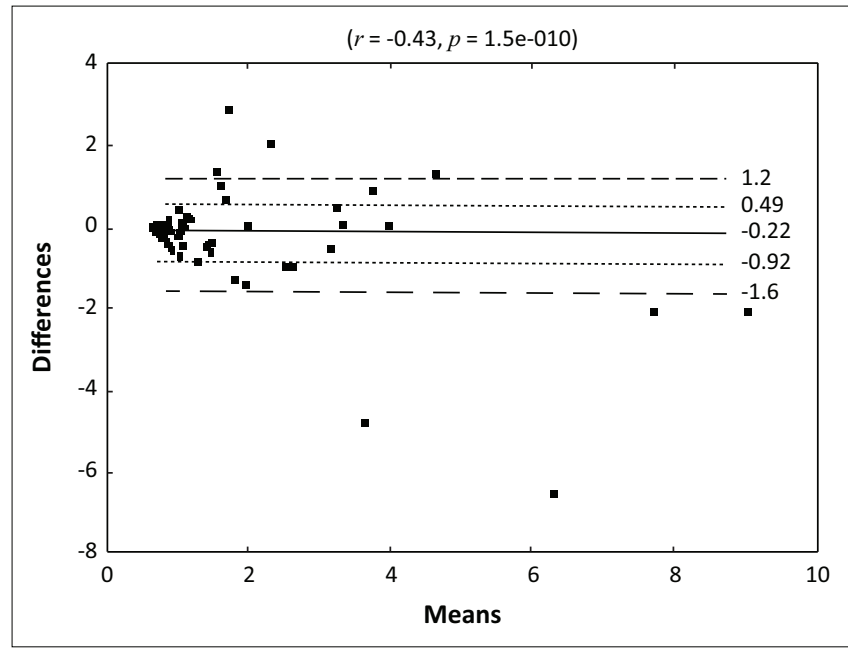

FIGURE 4: A Bland-Altman graph showing the agreement between scores of visual acuities (in $\mathrm{min}$ ) for left eyes obtained with a Snellen chart and Spectrum LogMAR chart. Units for differences and means in Figures 2-4 are minutes.

strabismus and other visual anomalies. Early detection of amblyopia is viewed as being of vital importance for effective treatment to be implemented within the sensitive period of neuroplasticity in the visual system. ${ }^{18,19,20,21}$ Nonetheless, other studies have found the evaluation of VAs to reliably screen only for myopia and not to accurately detect hyperopia or astigmatism. ${ }^{22,23}$ This study has therefore focused on the performance of children when VAs are evaluated using the SC and SLC.

\section{Distance visual acuities for both eyes, right eyes and left eyes}

The findings of the current study revealed that $83 \%, 73 \%$ and $83 \%$ for the right, left and both eyes, respectively, of the participants were found to have VAs in the normal range of $6 / 6$ or better using the conventional vision screening method. Using the SLC, the distribution of VAs in the normal range was $81 \%, 83 \%$ and $86 \%$ for the RE, LE and BE, respectively. The data of the current study on the SC and SLC were found to be consistent with the results of similar studies in which the prevalence of good VAs (6/6 or better) in the same age group was $\geq 85 \% .{ }^{24,25,26}$ However, a $10 \%$ difference of more participants (83\%) was found to have VAs in the normal range for the RE using the SLC compared to the SC. The findings of the two different methods are almost similar, with a difference of $\leq 3 \%$ for the LE and BE. The findings of similarities between the LE and BE using the two methods are consistent with those of the above - mentioned previous studies. Nonetheless, it should be borne in mind that previous studies used the SC only to evaluate the VAs, and the criteria used for a pass and fail were different from those of this study.

Contrary to the findings of our study, other studies compared the VAs measurements using the Eye Snellen iPad app and smartphone to a standard SC and found no significant differences between the methods..$^{8,9,10}$ However, the limitation for generalising the findings of these studies is that the method of sampling was purposive, with participants recruited from eye clinics, and the sample sizes were small. It should further be noted that in the above-mentioned studies, the advantages of using portable software were acknowledged, including the ability to randomise optotypes, user-friendliness and expediency, with which the researcher concurs. ${ }^{8,9,10}$ However, broader issues must be addressed for the incorporation of any mobile applications into the clinical setting, including information on the scientific validity of each application.

In comparing the sample means for results with the SC and SLC, they were found to be dissimilar, as shown in Table 1. Dissimilar means can be attributed to various factors related to the inherent characteristics (resolution vs recognition acuity) of the targets used in the two methods. The fundamental design flaws in the SC, including the non-geometric progression of letter sizes, the variable number of letters per line and the lack of a standardised scoring system, should be considered when this method is used for vision screening. ${ }^{1}$ The LogMAR charts used in the Spectrum Eyecare Software program were found previous studies to maintain a consistent ratio between optotypes and spacing, regardless of the angular subtense of the optotype, unlike the SC where each individual letter is assigned an individual score. ${ }^{11}$ The better performance of participants using the SLC in terms of the high scores of normal VAs, and a better mean, could also be attributed to the high resolution with which the computer screen is equipped, and the anti-glare screen protector used in the current study. Given that the VA scores using the SLC were identified as slightly better compared to the SC, the additional advantages of using this method are better contrast control and more flexibility in test options, together with the program being stimulating, rapid and easy to operate.

However, in an evidence-based update on VA measurements in children, a conclusion was reached that comparisons of VA measurements using different methods must be handled with caution..$^{27,28,29}$ The observed changes in VAs may reflect a change in the chart design rather than an actual change in visual function, and the current study supports this view. The current study's statistically significant differences $(p<0.05)$ were determined using paired correlation tests. A correlation that is statistically significant for the VAs, measured using the SC and SLC, was determined. However, the VAs of BE using the two methods were found to have a better level of agreement compared to the VAs obtained for the RE and LE using both methods.

\section{Conclusion}

This study has provided evidence that children of schoolgoing age (6-19 years) perform slightly better when the unaided VAs are evaluated using the SLC. However, the difference between the SLC and SC was found to be minimal (one-line difference), and both methods were identified as similar in detecting poor distance vision. Further validation of the SLC compared with the 'gold standard' (e.g. the Bailey Lovie or LogMAR ETDRS) is required for the assessment of VAs in children of schoolgoing age. But this study suggests that the methods are comparable and can be 
used in an interchangeable manner for vision screening purposes. However, the design problems of the SC still need to be addressed, related to accurately measuring VAs for children in the schoolgoing age group.

\section{Acknowledgements Competing interests}

The authors have declared that no competing interests exist.

\section{Authors' contributions}

W.J. and R.H. were supervisors for T.I.M.'s Doctoral in Philosophy study.

\section{Funding information}

This research received no specific grant from any funding agency in the public, commercial or not-for-profit sectors.

\section{Data availability statement}

Data sharing is not applicable to this article.

\section{Disclaimer}

The views and opinions expressed in this article are those of the authors and do not necessarily reflect the official policy or position of any affiliated agency of the authors.

\section{References}

1. Ricci F, Cedrone C, Cerulli, L. Standardized measurement of visual acuity. Ophthal Epidemiol. 1998;5(1):41-53. https://doi.org/10.1076/opep.5.1.41.1499

2. Flom MC, Weymouth FW, Kahneman D. Visual resolution and contour interaction J Opt Soc Am. 1963;53(9):1026-1032. https://doi.org/10.1364/JOSA.53.001026

3. Simmers AJ, Gray LS, McGraw PV, Winn B. Contour interaction for high and low contrast optotypes in normal and amblyopic observers. Ophthal Physiol Opt. 1999;19(3):253-260. https://doi.org/10.1046/j.1475-1313.1999.00416.x

4. Kulp MT, Dobson V, Peskin E, Quinn, G, Schmidt P. The electronic visual acuity tester: Testability in preschool children. Optom Vis Sci. 2004;81(4):238-244. https://doi.org/10.1097/00006324-200404000-00009

5. Trivedi RH, Wilson ME, Peterseim MM, Cole KB, Teed RGW. A pilot study evaluating the use of EyeSpy video game software to perform vision screening in school-aged children. J AAPOS. 2010;14(4):311-316. https://doi.org/10.1016/j. jaapos.2010.03.008

6. Sun JK, Aiello LP, Cavallerano JD, et al. Visual acuity testing using autorefraction or pinhole occluder compared with a manual protocol refraction in individuals with diabetes. Ophthalmol. 2011;118(3):537-542. https://doi.org/10.1016/j.ophtha.2010. 07.022

7. Perera C, Chakrabarti R, Islam, FMA, Crowston J. The Eye Phone Study: Reliability and accuracy of assessing Snellen visual acuity using smartphone technology. Eye (Lon). 2015;29(7):888-894. https://doi.org/10.1038/eye.2015.60
8. Zhang Z-T, Zhang S-C, Huang X-G, Liang L-Y. A pilot trial of the iPad tablet computer as a portable device for visual acuity testing. I Tel Telecare. 2013:19(1):55-59. https://doi.org/10.1177/1357633X12474964

9. Lodha VS. Comparison of visual acuity measurement by smartphone based application vs. conventional Snellen visual acuity chart. IJERMDC [serial online] 2015 [cited 10 May 2018];2(6);39-41. Available from: www.erpublications.com

10. Gounder PA, Cole E, Colley S, Hille DM. Validation of a portable electronic visual acuity system. J Mob Technol Med. 2014;3(2):35-39. https://doi.org/10.7309/jmtm.3.2.6

11. Tahir HJ, Murray IJ, Parry NRA, Aslam TM. Optimisation and assessment of three modern touch screen tablet computers for clinical vision testing. PLoS ONE. 2014;9(4):e95074. https://doi.org/10.1371/journal.pone.0095074

12. Bailey IL, Lovie JE. New design principles for visual acuity letter charts. Optom Vis Sci. 1976;53(11):740-745. https://doi.org/10.1097/00006324-197611000-00006

13. Declaration of Helsinki. World Medical Association [homepage on the Internet] n.d. [cited 2014 Jun 18]. Available from: http://www.wma.net/en/30publications/ 10policies/b3/index.html

14. Bland JM, Altman DG. Statistical methods for assessing agreement between two methods of clinical measurement. Lancet. 1986;327(8476):307-310.

15. Brink H, Van Der Walt C, Van Rensburg G. Fundamentals of research methodology for health care professionals. 2nd ed. Cape Town: Juta and Company; 2006.

16. Proctor SE. To see or not to see: Screening the vision of children in school. In Department of Education (Colorado) (editor). Guidelines for school vision screening programs: Kindergarten through to Grade 12 [homepage on the Internet]. 2006 [cited 2017 Feb 26]. Available from: https://www.cde.state.co.us/sites/default/ files/documents/healthandwellness/download/nurvisionguidelines.pdf

17. Press LJ, Moore BD. Clinical paediatric optometry. Boston: ButterworthHeinemann; 1993.

18. Xiang F, He M, Zeng Y, Mai J, Rose KA, Morgan IG. Increases in the prevalence of reduced visual acuity and myopia in Chinese children in Guangzhou over the past 20 years. Eye (Lon). 2013;27(12):1353-1358. https://doi.org/10.1038/eye.2013.194

19. Jakobsson $P$, Kvarnström G, Lennerstrand G. Screening for visual and ocular disorders in children, evaluation of the system in Sweden. Acta Paediatr. 1998;87(11):1173-1179. https://doi.org/10.1080/080352598750031176

20. Logan NS, Gilmartin B. School vision screening, ages 5-16 years: The evidencebase for content, provision and efficacy. Ophthal Physiol Opt. 2004;24(6):481-492. https://doi.org/10.1111/j.1475-1313.2004.00247.x

21. Williams WR, Latif AHA, Hannington L, Watkins DR. Hyperopia and educationa attainment in a primary school cohort. Arch Dis Child. 2005;90(2):150-153. https://doi.org/10.1136/adc.2003.046755

22. Mathers $M$, Keyes $M$, Wright, M. A review of the evidence on the effectiveness of children's vision screening. Child: Care Health Dev. 2010;36(6):756-780. https://doi.org/10.1111/j.1365-2214.2010.01109.x

23. Solebo AL, Rahi JS. Vision screening in children aged $4-5$ years. External review against programme appraisal criteria for the UK National Screening Committee [homepage on the Internet]. 2013 [cited 2013 Feb 25]. Available from: https:// legacyscreening.phe.org.uk/policydb_download.php?doc=365

24. Fotouhi A, KhabazKhoob M, Hashemi H, Yekta AA, Mohammad K. Importance of including refractive error tests in school children's vision screening. Arch Iran Med. 2011;14(4):250-253.

25. O’Donoghue L, McClelland JF, Logan NS, Rudnicka AR, Owen CG, Saunders KJ. Profile of anisometropia and aniso-astigmatism in children: Prevalence and association with age, ocular biometric measures, and refractive status. Invest Ophthalmol Vis Sci. 2013;54(1):602-608. https://doi.org/10.1167/iovs.12-11066

26. Ohlsson J, Villarreal G, Sjöström A, Abrahamsson M, Sjöstrand J. Visual acuity, residual amblyopia and ocular pathology in a screened population of 12-13-yearold children in Sweden. Acta Ophthalmol Scand. 2001;79(6):589-595. https://doi. org/10.1034/j.1600-0420.2001.790609.x

27. Naidoo KS, Raghunandan A, Mashige KP, et al. Refractive error and visual impairment in African children in South Africa. Invest Ophthalmol Vis Sci. 2003;44(9):3764-3770. https://doi.org/10.1167/iovs.03-0283

28. Ore L, Tamir A, Stein N, Cohen-Dar M. Reliability of vision screening tests for school children. J Nurs Scholarsh. 2009;41(3):250-259. https://doi.org/10.1111/ j.1547-5069.2009.01283.x

29. Anstice NS, Thompson B. The measurement of visual acuity in children: An evidencebased update. Clin Exp Optom. 2014;97(1):3-11. https://doi.org/10.1111/cxo.12086 